\section{Breaking Habits With Implementation Intentions: A Test of Underlying Processes}

Personality and Social Psychology Bulletin 37(4) $502-513$

(c) $201 \mathrm{I}$ by the Society for Personality

and Social Psychology, Inc

Reprints and permission:

sagepub.com/journalsPermissions.nav

DOI: $10.1177 / 0146167211399102$

http://pspb.sagepub.com

(SAGE

\author{
Marieke A. Adriaanse', Peter M. Gollwitzer 2,3, \\ Denise T. D. De Ridder', John B. F. de Wit ${ }^{1,4}$, and Floor M. Kroese'
}

\begin{abstract}
Implementation intentions specifying the replacement of a habitual response with an alternative response in a critical situation can overrule habits. In three experiments the cognitive effects of such counterhabitual implementation intentions were investigated. Results showed that implementation intentions eliminated the cognitive advantage of the habitual means in the "horse race" with the alternative response. That is, in the control condition, the habitual means was more accessible than the alternative means on encountering the critical situation, but this was no longer the case when implementation intentions were formulated. However, the cognitive advantage of the habitual means was not immediately replaced by an automatic activation of the alternative means. This suggests that formulating counterhabitual implementation intentions increases individuals' flexibility to choose which behavior to perform in the critical situation but that actual behavior will depart from their habits only to the extent that individuals have strong alternative goal intentions.
\end{abstract}

\title{
Keywords
}

breaking habits, implementation intentions, associations, accessibility, critical situation

Received February 26, 2010; revision accepted November 1, 2010

A substantial part of people's daily behavior is habitual (Aarts \& Dijksterhuis, 2000). Mindlessly opening a bag of chips when watching television, routinely ordering a beer when hanging out with friends, and consistently reaching for a bar of chocolate when feeling sad are all examples of habits. Habits develop as people repeatedly perform a specific behavior (e.g., opening up a bag of chips) in a stable situation (e.g., watching television) to pursue their goals. This cooccurrence between the situation and the behavior eventually creates a direct mental association between the situation and the behavior, which is strengthened each time they subsequently covary. Finally, this situation-behavior association is strengthened to the extent that when the situation is encountered, the behavior follows automatically (Aarts \& Dijksterhuis, 2000; Bargh \& Gollwitzer, 1994; Verplanken, 2006), that is, without awareness, unintentionally, efficiently, and with very limited controllability (Bargh, 1994).

Although habit formation allows individuals to perform their daily routines in a very efficient manner, it also has negative consequences. Individuals' intentions may change, for example, when someone with the habit of eating chips when watching television decides to start eating more healthily, while the association between the situation and the behavior remains. As the activation of the habitual behavior on encountering the critical situation occurs automatically, without the involvement of conscious intentions, chances are that one will find oneself sitting in front of the TV, stuffing a big handful of chips into one's mouth before even remembering the new intention to eat more healthily. In fact, a meta-analysis of studies on the intention-behavior relation showed that the most important moderator of this relation, and the most difficult factor to self-regulate, was the extent of habitual control over the behavior. When circumstances did not support habit formation, intentions had a large effect on behavior $(d=0.74)$. However, when circumstances supported the development of habits, this effect size dropped substantially ( $d=0.22$; Webb \& Sheeran, 2006).

\footnotetext{
'Utrecht University, Utrecht, Netherlands

${ }^{2}$ New York University, New York, NY, USA

${ }^{3}$ University of Konstanz, Konstanz, Germany

${ }^{4}$ University of New South Wales, Sydney, Australia

Corresponding Author:

Marieke A. Adriaanse, Utrecht University, Department of Clinical \& Health Psychology, PO Box 80 I40, 3508 TC Utrecht, Netherlands Email: M.A.Adriaanse@uu.nl
} 
Despite the numerous studies demonstrating how habits are created and affect behavior (e.g., Aarts \& Dijksterhuis, 2000; Danner, Aarts, \& De Vries, 2008; Verplanken \& Aarts, 1999), very little is known about effective ways to change habits once they are formed. One of the few approaches that have been suggested to change habits is to remove the critical stimulus that elicits the habitual response or to avoid the critical stimulus, for example by moving or changing jobs (Verplanken \& Wood, 2006). However, from a psychological perspective it is important to understand how people can self-regulate the habitual response in the presence of the critical stimulus. Such an approach would also be more practically applicable, as in real life it is often not possible to remove or avoid the critical stimulus; most people are unable to avoid "feeling sad" and would not like to quit "hanging out with friends" or "watching television."

\section{Implementation Intentions}

One self-regulatory strategy that has been proposed to support individuals in managing the critical stimulus in such a way that they are able to act on their counterhabitual intentions is to furnish one's intentions with implementation intentions (Adriaanse, De Ridder, \& De Wit, 2009; Gollwitzer, 1999; Gollwitzer \& Sheeran, 2006; Holland, Aarts, \& Langendam, 2006). Implementation intentions are simple action plans stipulating where, when, and how one will perform an intended behavior, which have been found to promote goal-directed action (Gollwitzer, 1999). Instead of simply specifying an end state one wants to reach, as is the case for intentions ("I intend to achieve Z"), implementation intentions specify the where, when, and how of reaching this end state and take the form of "If I am in situation X, then I will perform goaldirected behavior Y" (Gollwitzer, 1999). To illustrate, when formulating an implementation intention to support the intention to increase one's fruit intake, a specific situation that is a good opportunity to act on this intention is identified (e.g., "riding the bus home after work") and then linked to a specific goal-directed action (e.g., "eating an apple") in the if-then plan, resulting in the following implementation intention: "If I am riding the bus home after work, then I will eat an apple."

Planning one's goal striving in this manner is helpful for two reasons. First, by specifying a situation for enacting one's intentions in advance, the mental representation of this critical situation is highly accessible in memory and therefore more easily detected as a good opportunity to act on one's intentions. Second, by linking this critical situation to a specific goal-directed behavior in an if-then structure, the control of the behavior is delegated from the self to the specified situational cue, resulting in automatic elicitation of this goaldirected behavior when the situation is encountered (Bayer, Achtziger, Gollwitzer, \& Moskowitz, 2009; Gollwitzer, 1999;
Parks-Stamm, Gollwitzer, \& Oettingen, 2007). Indeed, numerous studies have demonstrated that implementation intentions promote the initiation of intended behaviors (e.g., Armitage, 2007; Sheeran \& Orbell, 1999) and that as a result of forming an implementation intention, the intended goal-directed behavior is initiated immediately (Cohen, Bayer, Jaudas, \& Gollwitzer, 2008), effortlessly (Brandstätter, Lengfelder, \& Gollwitzer, 2001; Gawrilow $\&$ Gollwitzer, 2008), and without conscious intent (Bayer et al., 2009).

\section{Implementation Intentions as a Strategy for Breaking Habits}

Several authors have noted that habits and implementation intentions seem to instigate similar automatic responses that differ only in origin, that is, whether they are the result of repeated action (i.e., habits) or reflect conscious planning (i.e., implementation intentions; e.g., Aarts \& Dijksterhuis, 2000). Based on this similarity, it has been suggested that implementation intentions could be used not only to promote the initiation of new, wanted behaviors but also to break existing unwanted habits. Specifically, it has been argued that when attempting to alter existing behavior patterns, implementation intentions could be used to link a new, desired behavior to the situation that previously triggered the habitual behavior (Adriaanse et al., 2009; Gollwitzer, 1999; Gollwitzer \& Sheeran, 2006; Holland et al., 2006). For example, a person who is aware that she or he tends to eat chips when watching television can use this information to formulate the following counterhabitual implementation intention: "If I am watching television and I want a snack, then I will reach for the fruit bowl and take an apple."

Indeed, in addition to the large body of studies demonstrating the efficacy of implementation intentions in promoting the initiation of new behaviors, evidence underscoring the potential of these counterhabitual implementation intentions in breaking existing habits has started to accumulate in recent years. Counterhabitual implementation intentions have been found effective in changing several types of habits, such as recycling habits (Holland et al., 2006), reducing switch costs in a task-switching paradigm and overcoming the automatic effects of spatial location in a Simon task (Cohen et al., 2008), reducing automatic stereotypical thoughts (Stewart \& Payne, 2008) or limiting the behavioral expression of implicit stereotypes (Mendoza, Gollwitzer, \& Amodio, 2010), reducing spider fear in spider phobics (Schweiger Gallo \& Gollwitzer, 2007; Schweiger Gallo, Keil, McCulloch, Rockstroh, \& Gollwitzer, 2009), reducing prompted disgust reactions (Schweiger Gallo et al., 2009), decreasing unhealthy snack consumption (Adriaanse et al., 2009), and reducing smoking behavior (but only for people with weak or moderately strong smoking habits; Webb, Sheeran, \& Luszczynska, 2009). 


\section{Processes by Which Implementation Intentions Overrule Habits}

Taken together, recent studies provide compelling evidence for the notion that implementation intentions that link a critical cue for a habitual response to an alternative response can effectively overrule habitual responses. Nevertheless, studies to date have been mainly concerned with establishing effects on behavioral outcomes, such as eating less unhealthy snacks (Adriaanse et al., 2009) or recycling plastic cups (Holland et al., 2006), and did not address the cognitive effects of formulating counterhabitual implementation intentions. In the present article, we aim to address this lack of understanding of underlying cognitive processes to gain further understanding of how implementation intentions help the new response to win the "horse race" with the habitual response.

Using an horse race metaphor, we hypothesize that the formation of a counterhabitual implementation intention cancels out the cognitive advantage of the habitual over the alternative means in winning the race. This hypothesis is in line with earlier findings. Several studies have shown that one of the mechanisms underlying the efficacy of implementation intentions is that they create a strong association between the cue and the response specified in the if-then plan (Bayer et al., 2009; Gollwitzer, 1999; Parks-Stamm et al., 2007; Webb \& Sheeran, 2007, 2008).

However, an intriguing and novel question then is why a new response would win the race with an old response when implementation intentions are geared toward breaking a habit. Holland and colleagues (2006) suggested that the newly created association between the situation and the alternative response may be stronger than the old association between the situation and the habitual action. However, it remains to be established whether a single act of planning can actually outweigh prolonged behavioral repetition. Although the association between the situation and the alternative response may - as we argue above-indeed be strengthened as a result of the counterhabitual implementation intention, it is unlikely that it is strengthened to such an extent that, without any changes to the situation-habitual response association, it will outrun the activation of the habitual response.

A further possibility suggested by Holland and colleagues (2006) is that the formation of a counterhabitual implementation intention inhibits the habitual response because it interferes with the alternative response specified in the implementation intention. This suggestion seems plausible when considering previous theoretical and empirical work. Kruglanski et al.'s (2002) goal systems theory in particular offers a supportive conceptual rationale. Goal systems theory assumes that means that are instrumental in attaining a goal are connected to this goal by a facilitative link, whereas the connection between two alternative means to achieve the same goal is inhibitory (Kruglanski et al., 2002). In other words, according to goal systems theory, if a goal activates one means, the activation of an alternative means for this goal is inhibited. Related to this notion are findings that inhibitory links exist between two subgoals serving the same overarching goal (in which case the two subgoals could be considered the means for attaining the overarching goal; Shah, Friedman, \& Kruglanski, 2002). In addition, research by Danner, Aarts, and De Vries (2007) has shown that when participants repeatedly retrieve one means for a specific goal, competing means for this same goal become inhibited.

Still, the current research is not concerned with goalmeans relations but rather with associations between situations and behavioral responses. Nevertheless, it is generally agreed that habit formation is the result of repeatedly performing a certain behavior (e.g., eating chocolate) in the same concrete situation (e.g., feeling sad) to attain a specific goal (e.g., to soothe oneself), and that only after some repeated occurrence the behavioral response becomes triggered directly by the situation (Verplanken, 2006). It thus seems appropriate to extrapolate suggestions from goal systems theory (Kruglanski et al., 2002) and findings by Shah et al. (2002; Danner et al., 2007) to situation-behavior associations. If this parallel can indeed be drawn, this would engender strong conceptual support for the idea that when a situational cue becomes strongly linked to a new behavior through the formation of a counterhabitual implementation intention, the link with the old habitual behavior is weakened simultaneously, and these combined effects yield our hypothesized result of the habitual means no longer having an advantage in the race with the alternative means.

\section{Research Overview}

Three studies were designed to investigate our hypothesis. In Study 1, participants formulated implementation intentions that either specify the replacement of a habitual snack they usually take at home by an alternative snack or that specify the replacement of a habitual drink they usually take in a bar by an alternative drink. A pilot study indicated that these are goals that students, the participants in our studies, frequently pursue in this context, and for which they generally use strong habitual means. The strength of the cue-response associations will subsequently be assessed in a primed lexical decision task. Study 2 is similar to Study 1, except that this time participants were specifically asked to plan to replace their habitual snack or drink by a healthier alternative. In Study 3, the focus is on entirely personal habits; participants were asked to generate not only their own personal habitual and alternative snacks but also their own personal critical cue for snacking. In addition, a more stringent control condition was put in place. 


\section{Study I}

In Study 1, a primed lexical decision task is used to compare the accessibility of the habitual response and the alternative response on encountering the critical cue between a control condition and a counterhabitual implementation intention condition.

\section{Method}

Participants. In exchange for $€ 3$ or course credit, 64 female students participated. ${ }^{1}$ After excluding 3 participants because they were very slow in responding to the four targets in the primed lexical decision task $(S D>3.5 ; n=2)$ or because they indicated to have been aware of the prime-target relation in the lexical decision task $(n=1)$, the final sample consisted of 61 participants with a mean age of 19.90 years $(S D=1.94)$ and a mean BMI of $21.28(S D=2.67)$.

Procedure and design. The experiment had a 2 Type of Means (habit vs. alternative) $\times 2$ Strategy (implementation intention vs. control) within-subjects design and consisted of three tasks. Participants started with a means-generation task in which they generated their habitual and an alternative means for snacking at home and drinking in a bar. Half of the participants were then asked to formulate an implementation intention to replace their habitual snack by an alternative snack, and the other half of the participants were asked to formulate an implementation intention to replace their habitual drink by an alternative drink. So for which behavior (snacking at home or drinking in a bar) the implementation intention was formulated was counterbalanced across participants. Last, a primed lexical decision task was employed to measure the accessibility of the two habitual and the two alternative means. All tasks were completed on a desktop computer, and participants were seated in individual cubicles.

Means-generation task. In the means-generation task, participants were asked to provide a habitual and an alternative means for each of two situations: "snacking when being at home" and "drinking in a bar." After the habitual means was generated, participants listed an alternative means: They were asked which snack/drink they would eat/drink in this situation (at home or in a bar) if their habitual means were not available. These idiosyncratic habitual and alternative means were subsequently used as target stimuli in the primed lexical decision task.

Implementation intentions. After participants had generated their two habitual and two alternative means, they were asked to form an implementation intention for replacing one of their two habitual means by the corresponding alternative means. Which of the two alternative means (i.e., the alternative means for snacking or the alternative means for drinking) was supported by a counterhabitual implementation intention was counterbalanced between participants. The formulation of the implementation intention was designed in such a manner that the critical situation for the habitual means (i.e., being at home or being in a bar) was linked to the corresponding alternative means (e.g., fruit or soda, respectively).

The formation of the counterhabitual implementation intention was introduced in the next task. To increase commitment to the implementation intentions formed, participants were told the following story:

Flexibility is a very beneficial trait to have. People who have various means for the same goal are much more likely to achieve their goals. They are much more efficient and effective in achieving their daily goals. In order for you to become more efficient and effective, we would like you to make a plan which will increase your capacity to be flexible.

Then, participants received the following instructions to form the implementation intentions:

Screen 1: At the start of this study you indicated that you usually take [habitual means] to snack/drink when you are at home/in a bar. Now we would like to ask you to plan to take [alternative] next week every time that you are at home/ in a bar and want to snack/drink.

Screen 2: The plan we would like you to make has the following format: "If I am at home/in a bar, and I want to snack/drink then I will take [alternative]." Please repeat this statement in your mind a few times. This is important because we would like you to try and stick to your plan in the coming week.

Screen 3: Now please try to envision yourself acting out your plan: "If I am at home/in a bar, and I want to snack/drink then I will take [alternative]."

Screen 4: Now please type the plan you just envisioned yourself acting out below.

Primed lexical decision task. Before starting the primed lexical decision task, which was presented as a separate study, participants were told that in this task they should press a left or a right key to indicate as quickly and accurately as possible if a presented word was an existing word or not (which key corresponded to "word" and which to "nonword" was counterbalanced across participants). Participants were informed that this task could include words they had generated in the previous experiment. This was done to ensure that participants would not be surprised to see these words and therefore respond slower. Participants started with a practice run, consisting of eight trials, before moving on to the actual primed lexical decision task. 
Personality and Social Psychology Bulletin 37(4)

A trial in the primed lexical decision task started with a fixation cross $(1,000 \mathrm{~ms})$. Then, participants were presented with a word $(50 \mathrm{~ms})$, which in case of the critical targets (the four means) was the critical situation ("home" or "bar"). Following this prime, a string of X's ("xxxxx. ..") was presented as a backward mask (700 ms), and then the word or nonword that participants were supposed to respond to by pressing on a left or right key appeared on screen. After participants responded, a blank intertrial screen $(2,000 \mathrm{~ms})$ was presented.

The primed lexical decision task encompassed 32 trials. Targets included the four means participants had generated, four irrelevant words (stairs, clock, saddle, wheels), and eight nonwords (all targets were presented twice, once in Block 1 and once in Block 2). Primes included the situations of home and bar (the idiosyncratic means where always preceded by the corresponding situation prime) or one of four irrelevant words that were related to the irrelevant targets (e.g., tower for clock).

Although using idiosyncratic material allows us to truly test the cognitive effects of implementation intentions on personal habits, a drawback of this method is that the number of critical trials is limited to the number of options generated by the participants (i.e., four target means, in this case). However, previous work on the activation of the mental representation of goals and plans has successfully used only very few critical trials as well (e.g., Adriaanse, Van Oosten, De Ridder, De Wit, \& Evers, 2011; Fishbach, Friedman, \& Kruglanski, 2003). In fact, Adriaanse, Van Oosten, et al.'s (2011) findings indicated that a study including a similar limited number of critical trials (Study 1) yielded results that were comparable to a study that included more critical trials (Study 2).

Debriefing. At the end of the experiment participants were asked to write down anything they noticed about the experiment. Also, participants' demographic characteristics were assessed (including height and weight) and participants were debriefed, thanked for their participation, and reimbursed with $€ 3$ or course credit.

\section{Results}

A repeated measures analysis of variance (ANOVA) was performed with Type of Means (habit vs. alternative) and Strategy (implementation intentions vs. control) as within-subjects variables and the natural $\log$ transformed reaction times for critical targets (i.e., the four means) to which subjects responded correctly ( $95 \%$ of trials) as the dependent variable. ${ }^{2}$ In this analysis, reaction times for the two behaviors (snacking at home vs. drinking in a bar) were thus combined so that each participant had a score for each of the four targets (habitual means-control, alternative means-control, habitual means-implementation intention, alternative meansimplementation intention). This combining of reaction times for the two behaviors was justified as a similar analysis in
Table I. Mean Response Latencies and Standard Deviations of the Habitual and Nonhabitual Means, Study I

\begin{tabular}{lccc}
\hline & & $\begin{array}{c}\text { Habitual } \\
\text { means }\end{array}$ & $\begin{array}{c}\text { Alternative } \\
\text { means }\end{array}$ \\
\hline Control & $M$ & 621.00 & 675.40 \\
Implementation intention & $S D$ & 161.98 & 276.39 \\
& $M$ & 649.46 & 638.34 \\
& $S D$ & 165.60 & 197.79 \\
\hline
\end{tabular}

which Behavior (snacking at home and drinking in a bar) was included as a between-subjects factor, did not yield any significant two-way or three-way interactions with behavior (all $p \mathrm{~s}>.28$ ) indicating that counterbalancing was effective and effects were similar for both behaviors.

The 2 Type of Means (habit vs. alternative) $\times 2$ Strategy (implementation intentions vs. control) ANOVA revealed no significant main effects, $F_{\mathrm{s}}<1$, but did show a significant cross-over interaction of Type of Means $\times$ Strategy, $F(1,57)=4.39, p<.05, \eta_{p}^{2}=.07$. Simple main effects within the control condition revealed that participants reacted quicker to the habitual means compared to the alternative means, $F(1,59)=4.28, p<.05, \eta_{p}{ }^{2}=.07$. However, in the implementation intention condition, there was a nonsignificant effect of type of means in the other direction, $p=.10$ (see Table 1 for nontransformed mean response latencies).

\section{Discussion}

We observed that forming counterhabitual implementation intentions had the hypothesized result that the habitual means no longer had a cognitive advantage over the alternative means. One limitation of Study 1 is that goal commitment was not assessed. This is important because previous research has indicated that overall levels of goal intentions affect the effectiveness of implementation intention interventions (Sheeran, Webb, \& Gollwitzer, 2005).

Another limitation is that, after close inspection, we found that the habitual and alternative means that participants generated for each of the situations were in general equally healthy or unhealthy (e.g., "chocolate" as the habitual means for snacking and "cookies" as the alternative means for snacking). In real life, and in previous studies on counterhabitual implementation intentions (e.g., Adriaanse et al., 2009; Webb et al., 2009), the habits that people aim to change usually relate to replacing unhealthy responses by more healthy responses, such as replacing chocolate by apples. Replacing chocolate by cookies might be easier than replacing chocolate by apples, as cookies may be more similar to chocolate in terms of their hedonic value than apples and may therefore already be more strongly linked to the critical situation. To test the cognitive effects of implementation intentions specifying to replace an 
unhealthy habitual response with a healthy alternative, a second study was conducted.

\section{Study 2}

In Study 2 it was tested whether our hypothesis could also be supported for implementation intentions linking a healthier alternative to a critical situation. Measures of habit strength and healthiness of the means were included to assess whether the manipulation in the means-generation task was successful.

\section{Method}

Participants. In exchange for $€ 3$ or course credit, 34 female students participated. After excluding 4 participants because they were very slow in responding to the four targets in the primed lexical decision task $(S D>3.5 ; n=1)$ or because they indicated to have been aware of the prime-target relation in the lexical decision task $(n=3)$, the final sample consisted of 30 participants with a mean age of 20.70 years $(S D=1.73)$ and a mean BMI of $21.64(S D=2.34)$.

Procedure and design. The procedure and design were similar to Study 1 . The experiment again had a 2 Type of Means (habit vs. alternative) $\times 2$ Strategy (implementation intention vs. control) within-subjects design and consisted of three tasks: the means-generation task, the forming of implementation intentions, and the primed lexical decision task.

Means-generation task. The means-generation task was similar to Study 1 except that this time participants were asked to generate alternative means which were healthier than their self-generated habitual means for snacking when being at home and drinking in a bar.

Implementation intentions. The implementation intention formation task was also similar to Study 1, except for the cover story. This time no cover story about flexibility was required as participants were informed that the plan to take their alternative snack or drink next week served the purpose of helping them snack or drink more healthily.

Primed lexical decision task. The primed lexical decision task was similar to Study 1. Again, the primed lexical decision task encompassed 16 different targets; the 4 means participants had generated, 4 irrelevant words and 8 nonwords, and each of the 16 trials were presented twice (once in each of two blocks). Like in Study 1, the 4 trials including the means participants had generated as targets were always preceded by the corresponding situation, whereas the 4 irrelevant words were preceded by a related word. The nonwords were preceded by the same primes that were also used for the 4 targets and the 4 irrelevant words.

Measures. Several assessments were added. First, after the means-generation task, participants were asked to indicate for each of the four means (a) the frequency of using the means ("How often did you snack on/drink [means] at home/in a bar in the past four weeks?") and (b) the stability of the situation when using the means ("How similar are the circumstances every time you snack on/drink [means] at home/in a bar?"), which was assessed using 9-point scales ranging from 1 (very different circumstances) to 9 (very similar circumstances). Habit strength was then calculated by multiplying the frequency and stability scores (Danner et al., 2008).

Subsequently, participants were asked to indicate the extent to which they were committed to the goals outlined in the description of the study ("How committed are you to your plan to eat less unhealthy snacks/drink less unhealthy drinks in the coming days"), with responses given on a 5 -point scale ranging from 1 (totally disagree) to 5 (totally agree). Participants were also asked to rate the healthiness of each of the means ("How healthy is [means]?") on 5-point scales ranging from 1 (very unhealthy) to 5 (very healthy).

Debriefing. Procedures for debriefing were similar to Study 1.

\section{Results}

Descriptives. Participants were committed to eat less unhealthy snacks or drink less unhealthy drinks in the coming days $(M=3.20, S D=0.85)$.

Manipulation check: Habit strength. A repeated measures ANOVA was performed with Type of Means (habit vs. alternative) as a within-subjects factor and habit strength as dependent variable. This analysis revealed that our manipulation was effective: There was a significant main effect of Type of Means, $F(1,29)=9.78, p<.01, \eta_{p}^{2}=.25$, indicating that overall the habitual means $(M=57.87 S D=31.22)$ were rated higher on habit strength than the alternative means $(M=35.33$, $S D=34.60)$.

Manipulation check: Healthiness. A similar repeated measures ANOVA was performed on healthiness. This analysis revealed that our manipulation was also effective with respect to healthiness: We found a significant main effect of Type of Means, $F(1,29)=71.35, p<.01, \eta_{p}{ }^{2}=.71$, indicating that overall the habitual means $(M=2.20, S D=0.66)$ were rated as less healthy than the alternative means $(M=4.01$, $S D=0.95)$.

Main analyses. A repeated measures ANCOVA was performed for the natural log transformed reaction times for targets to which subjects responded correctly (96\%), with Type of Means (habitual vs. alternative) and Strategy (implementation intentions vs. control) as within-subjects variables (for mean nontransformed response latencies, see Table 2) and commitment as a covariate as this variable correlated with our dependent measure. Similar to Study 1, reaction times for the two behaviors (snacking at home and drinking in a bar) were combined so that each participant had a score for each of the four targets (habitual meanscontrol, alternative means-control, habitual means-implementation intention, alternative means-implementation intention). Again, a repeated measures ANCOVA in which 
Table 2. Mean Response Latencies and Standard Deviations of the Habitual and Nonhabitual Means, Study 2

\begin{tabular}{lccc}
\hline & & $\begin{array}{c}\text { Habitual } \\
\text { means }\end{array}$ & $\begin{array}{c}\text { Alternative } \\
\text { means }\end{array}$ \\
\hline Control & $M$ & 603.26 & 654.21 \\
& $S D$ & 128.69 & 219.98 \\
Implementation intention & $M$ & 681.00 & 623.66 \\
& SD & 314.19 & 158.72 \\
\hline
\end{tabular}

Behavior was included as a between-subjects factor indicated that combining the reaction times for the two behaviors was justified, as this analysis did not yield any significant two-way or three-way interactions with Behavior (all $p \mathrm{~s}>.15)$.

The analysis revealed no significant main effects, $F_{\mathrm{S}}<1$, but did reveal a significant two-way interaction of Type of Means $\times$ Strategy, $F(1,27)=4.01, p=.05, \eta_{p}{ }^{2}=.13$. Simple comparisons showed that participants reacted marginally significantly quicker to the habitual means compared to the alternative means in the control condition, $F(1,28)=5.32, p=$ $.06, \eta_{p}{ }^{2}=.07$. However, in the implementation intention condition there was a nonsignificant effect of type of means in the other direction, $p=.18$.

\section{Discussion}

Results from Study 2 showed that implementation intentions linking a critical cue for the habitual response to a healthier alternative can alter the chances for the habitual and alternative responses of winning the horse race for activation on being primed with the critical cue. Similar to Study 1, when not forming a counterhabitual implementation intention, the habitual means was more accessible than the alternative means on encountering the critical cue, but after forming counterhabitual implementation intentions this was no longer the case. Study 2 thus replicated results from Study 1 and extended our previous findings by showing that this effect can also be found when implementation intentions are aimed at replacing an unhealthy habit with a healthier alternative. However, the present findings do not rule out the possibility that similar effects could also be obtained by merely instructing participants to form strong intentions rather than by formulating implementation intentions. Therefore, a third study was conducted to address this issue.

\section{Study 3}

In Study 3 the implementation intention condition was compared to an intention only condition to provide a more stringent test of our hypotheses. Moreover, the effects of implementation intentions on entirely personal critical cue-habitual response and personal critical cue-alternative response associations were assessed, rather than using precoded critical cues.

\section{Method}

Participants. In exchange for $€ 3$ or course credit, 80 female students participated. After excluding 3 participants with extreme scores on one of the two targets $(S D>3.5)$ and 2 participants with extreme scores on habit strength $(S D>3.5)$, the final sample consisted of 75 participants with a mean age of 21.20 years $(S D=1.85)$ and a mean BMI of $21.91(S D=2.34)$.

Procedure and design. The experiment had a 2 Type of Means (habit vs. alternative; within subjects) $\times 2$ Strategy (goal intention vs. goal intention + implementation intention; between subjects) design. Similar to Studies 1 and 2, the experiment consisted of three tasks, a means-generation task, a forming implementation intentions task, and a primed lexical decision task, which were performed on a computer in separate cubicles.

Unlike Studies 1 and 2, in this study, only the goal of snacking was used. This was deemed necessary as a pilot study in which two goals were used (snacking and drinking, similar to Study 1 and 2) indicated that the personal critical cues participants listed for unhealthy snacking were often similar to the personal critical cues for unhealthy drinking. As such crossover associations between the two goals would severely distort results in the primed lexical decision task, it was therefore decided to use only the goal "snacking" in Study 3.

Means-generation task. The means-generation task was similar to Study 2, except that this time only means for the goal of snacking were used. Moreover, after generating their habitual snack, participants were now asked to generate a critical situation for eating this habitual snack themselves. Participants were instructed to describe in one word the critical situation for eating their habitual snack and were told that this critical situation should represent their most frequently occurring reason for eating the habitual snack (Adriaanse et al., 2009). Furthermore, participants were told that this critical cue could be anything, such as a time of day, a feeling, a place, an activity, or certain company. Similar to Study 2, participants were then asked to generate a healthier alternative snack that they could eat whenever they encountered their critical situation.

Implementation intentions. Participants in both conditions were asked to first formulate a goal intention to eat less of their habitual snack. They were asked to commit themselves to this intention and to repeat it to themselves several times. Participants in the implementation intention condition were then asked to supplement this goal intention with a counterhabitual implementation intention. Instructions for formulating the implementation intention were similar to Study 2.

Primed lexical decision task. The primed lexical decision task was similar to Studies 1 and 2, but because only means for the goal of snacking were included in this study, the 16 targets now entailed, next to 8 nonwords, 2 means and 6 irrelevant words (stairs, clock, wheels, kneecap, ferry, platform). Again, each of the 16 trials was presented twice (once in each of 
two blocks), and the critical targets (the two snacking means) were always preceded by the corresponding situation, whereas the 6 irrelevant words were preceded by a related word (e.g., tower-clock).

Measures. The same assessments for habit strength, goal commitment, and healthiness that were used in Study 2 were included. However, goal commitment was now assessed using three items ("I intend/plan/want to eat less unhealthy snacks in the coming days"), with response scales ranging from 1 (totally disagree) to 5 (totally agree), Cronbach's $\alpha=$ .89. In addition, the hedonic value of each of the two means was assessed to control for unintended differences in hedonic value between the two conditions. For both means the hedonic value was assessed by three items ("Eating [means] is tasty/enjoyable/pleasant") that could be answered on 5-point scales ranging from 1 (totally disagree) to 5 (totally agree), Cronbach's $\alpha \mathrm{s}=.81$.

Debriefing. Procedures for debriefing were similar to Studies 1 and 2.

\section{Results}

Descriptives. On average, participants had strong intentions to eat fewer unhealthy snacks $(M=3.95, S D=0.68)$. Participants rated both the habitual snack $(M=4.25, S D=0.50)$ as well as the alternative snack as having high hedonic value $(M=3.93, S D=0.58)$.

Randomization check. Separate ANOVAs for age, BMI, intention, hedonic value of the habitual means, hedonic value of the alternative means, mean reaction time to nonwords, and mean reaction time to neutral words with Strategy (intention vs. intention + implementation intention) as the independent variable were performed to check whether randomization was successful. None of the ANOVA's showed any significant effects, indicating successful randomization.

Manipulation check: Habit strength. A repeated measures ANOVA was performed for habit strength scores with Type of Means (habit vs. alternative) as the within-subjects variable and Strategy (intention vs. intention + implementation intention) as a between-subjects variable. This analysis revealed that our manipulation was effective, as there was a main effect of Type of Means, $F(1,73)=47.77, p<.01$, $\eta_{p}{ }^{2}=.40$, indicating that overall the habitual means $(M=60.96$, $S D=40.25)$ were rated higher on habit strength than the alternative means $(M=26.37, S D=29.11)$. There was no significant Type of Means $\times$ Strategy interaction, $p=.32$, indicating that the effect of Type of Means on habit strength was equally strong across the two strategy conditions.

Manipulation check: Healthiness. A similar repeated measures analysis was performed on healthiness. This analysis revealed that our manipulation was also effective regarding perceived healthiness, as there was a main effect of Type of Means, $F(1,73)=404.74, p<.01, \eta_{p}{ }^{2}=.85$, indicating that overall the habitual means $(M=2.01, S D=0.65)$ were rated
Table 3. Mean Response Latencies and Standard Deviations of the Habitual and Nonhabitual Means, Study 3

\begin{tabular}{lccc}
\hline & & $\begin{array}{c}\text { Habitual } \\
\text { means }\end{array}$ & $\begin{array}{c}\text { Alternative } \\
\text { means }\end{array}$ \\
\hline Control & $M$ & 599.14 & 698.78 \\
Implementation intention & SD & 175.82 & 348.05 \\
& $M$ & 646.42 & 624.28 \\
& SD & 221.43 & 155.57 \\
\hline
\end{tabular}

as less healthy than the alternative means $(M=4.32, S D=$ 0.74). There was no significant Type of Means $\times$ Strategy interaction, $p=.64$, indicating that the effect of type of means on healthiness was equal across the two strategy conditions.

Main analyses. A repeated measures ANOVA was performed for the natural $\log$ transformed reaction times of trials to which subjects responded correctly (96\%) with Type of Means as the within-subjects variable and Strategy as the between-subjects variables (for mean nontransformed response latencies, see Table 3). This analysis revealed no significant main effect of Type of Means, $p=$ .14 , but did reveal a significant interaction of Type of Means $\times$ Strategy, $F(1,73)=4.64, p<.05, \eta_{p}{ }^{2}=.06$. Simple comparisons within the two strategy conditions revealed that whereas in the goal intention condition participants reacted significantly quicker to the habitual means compared to the alternative means, $F(1,38)=5.02, p<.05$, $\eta_{p}{ }^{2}=.12$, there was a nonsignificant effect of Type of Means in the other direction within the implementation intention condition, $F<1$.

\section{Discussion}

Study 3 replicates findings from Studies 1 and 2, as again a significant Type of Means $\times$ Strategy interaction was found, indicating that after formulating a counterhabitual implementation intention the habitual means no longer showed a stronger mental link to the critical situation than the alternative means. It is important to note that as participants chose their own habitual snacks as well as their most important critical cue for eating this habitual snack, the habits (cue-habitual means associations) that participants generated were stronger and thus more difficult to change compared to the previous two studies: In Study 3 the difference in mean habit strength for the habitual versus alternative means was about 1.5 times larger than in Study 2, even though in both studies participants were required to generate a healthier alternative. Nevertheless, even for these strong habits, the implementation intentions resulted in the intended outcome: After formulating a counterhabitual implementation intention, the habitual means no longer had a cognitive advantage in the horse race with the alternative means on encountering the critical cue. 


\section{General Discussion}

Recent research has convincingly shown that implementation intentions can be effective in overruling habitual behaviors when specifying that the habitual response shall be replaced with an alternative new response once the critical situation is encountered (Adriaanse et al., 2009; Cohen et al., 2008; Holland et al., 2006; Mendoza et al., 2010; Schweiger Gallo et al., 2009; Schweiger Gallo \& Gollwitzer, 2007; Stewart \& Payne, 2008). In the present research, we investigated the cognitive effects of forming counterhabitual implementation intentions to increase the understanding of what makes counterhabitual implementation intentions such effective tools to overrule habits. We hypothesized that as a consequence of forming a counterhabitual implementation intention, the associative link between the cue and the alternative response is strengthened while the cue-habitual response link is simultaneously inhibited, and that these effects combined cancel out the advantage of the habitual over the alternative means once the race is started on cue activation.

Three studies were conducted to investigate our horse race metaphor hypothesis. Study 1 supported this hypothesis by showing that although in the control condition the habitual means was more accessible than the alternative means, in the implementation intention condition this was no longer the case. Study 2 replicated these findings for implementation intentions that linked the critical cue for a habitual response to a healthier alternative. Last, in Study 3 habits were entirely idiosyncratic as participants were now required to also selfgenerate the critical cue for their habitual snack. This is an important addition to Studies 1 and 2, as recent research has indicated that, to be most effective, counterhabitual implementation intentions should target truly personal critical cues that represent the actual reason for the habitual behavior (Adriaanse et al., 2009). Similar to in Studies 1 and 2, results supported our hypothesis: In the implementation intention condition the advantage of the habitual means over the alternative means was eliminated.

Taken together, the present studies illuminate the cognitive effects that may be induced by formulating counterhabitual implementation intentions and thus shed some light on the processes that may underlie the efficacy of implementation intentions in breaking habits. Our results show that implementation intentions that link a critical cue for a habitual response to an alternative response cause the habitual and alternative means to become equally accessible. This signifies that, as a result of formulating counterhabitual implementation intentions, individuals can return to the type of action control that existed before any habit was created in the first place - that is, there is no habitual response that can easily outrun other responses. It is important to note, however, that our findings also suggest that the formation of a counterhabitual implementation intention does not immediately replace the old habit by a new habit, as the alternative means does not become significantly more accessible than the habitual means on cue activation. In other words, the old habitual and the new alternative responses are now truly competitive in winning the race of early activation.

However, although a new habit is not created as a direct result of forming a counterhabitual implementation intention, it is most likely only a matter of time before a new habit is established. In the first instance, for implementation intentions to show their effects, a strong goal intention to use an alternative means is still required to quickly activate the alternative means in the critical situation. If this new alternative means is subsequently repeatedly chosen in the critical situation, the mental link between the situation and this new means is strengthened further, which eventually will lead to the automatic activation of this means on encountering the situation (Aarts \& Dijksterhuis, 2000; Verplanken, 2006). The presence of a strong goal intention is then no longer required to back up the respective implementation intention; in other words, a new habit has been formed.

The present findings underscore the importance of establishing strong goal intentions in future research and interventions that seek to apply the forming of implementation intentions to overcome unwanted habits. That is, when the habitual and the alternative responses have equal chances of winning the cognitive horse race, actual behavior will depart from habits only to the extent that individuals have strong alternative goal intentions. Although most studies that employ the formation of implementation intentions to support the initiation of new behaviors already ensure that participants hold strong underlying goal intentions (Sheeran, Webb, et al., 2005), for implementation intentions aimed at diminishing existing habits the importance of goal intentions may easily be overlooked. As habits are usually equated with automaticity and a lack of conscious control (Aarts \& Dijksterhuis, 2000), intentions may not be perceived as important. The present research, however, stresses the importance of strong intentions in interventions using counterhabitual implementation intentions to break habits.

\section{Limitations and Suggestions for Future Research}

Several limitations have to be noted. First, our studies included women only as we expected that results may be different for men (e.g., because of a weaker motivation to eat less unhealthily among men). Future research is therefore necessary to investigate whether the obtained results will also hold in a male sample.

Second, although the present studies contribute to our understanding of the cognitive effects of implementation intentions targeting unwanted habits, an ultimate test of the importance of underlying processes involves simultaneously investigating both cognitive and behavioral effects 
and establishing their relation to each other. Although future research should be conducted to relate cognitive effects to behavioral outcomes, it is, however, important to note that a direct relation between changes in the cognitive accessibility of means and changed actions may be difficult to obtain for long-term behavioral assessment (e.g., food intake over several days), which is required for studies on habits. The accessibility of the cue-means relations is not static: By repeatedly enacting the implementation intention, the association between the cue and the new behavior will strengthen even further. So although relating cognitive and behavioral effects may certainly be an interesting avenue for future research, there are reasons to believe that it may be difficult to relate cognitive accessibility measured right after the manipulation to behavior over a longer period of time (Holland et al., 2006).

Third, although using idiosyncratic material is a major strength of the present studies, it also has its drawbacks, as the word length and frequency of these targets in the lexical decision task could not be matched to world length of the neutral targets. However, in Studies 1 and 2 both independent variables were manipulated within subjects, and in Study 3, where Strategy was manipulated between subjects, targets were entered by participants before they were randomly distributed across study conditions. Therefore, for all three studies it is quite unlikely that this lack of control over the linguistic qualities of the targets has severely influenced the reliability of our findings.

It is also important to note that in this series of experiments we studied only one specific type of counterhabitual implementation intention, whereas several variants of implementation intentions have been proposed for breaking or suppressing habitual responses (Gollwitzer, Bayer, \& McCulloch, 2005; Sheeran, Milne, Webb, \& Gollwitzer, 2005). In addition to implementation intentions that specify the replacement of a habitual response with an alternative response - as was tested in the present research ("If $x$, then alternative response $z$ ")-implementation intentions specifying the negation of the habitual response ("If $x$, then not $y$ ") and implementation intentions specifying ignoring the triggering stimulus or critical cue ("If $x$, then ignore $x$ ") have been suggested for overcoming habitual responses (Gollwitzer et al., 2005; Sheeran, Milne, et al., 2005).

However, in recent empirical tests negation plans have not been found effective in breaking habits (Adriaanse, Van Oosten, et al., 2011; Otis \& Pelletier, 2008; but for positive findings, see Sullivan \& Rothman, 2008), and explanations for their lack of effect are being investigated (Adriaanse, Van Oosten, et al., 2011). In contrast, implementation intentions that specify an ignore response have been found to be effective in overcoming habits (Achtziger, Gollwitzer, \& Sheeran, 2008; Mendoza et al., 2010; Schweiger Gallo et al., 2009; Sheeran, Aubrey, \& Kellett, 2007), but, similar to replacement implementation intentions, little is known about the underlying processes that make this type of plan effective in overruling habitual responses. A further investigation of underlying processes is thus also warranted for implementation intentions that specify ignoring a critical stimulus.

A further limitation is that although we tried to target participants' personal habits by letting them identify their own personal critical cues (Study 3), this procedure may not have been optimal. For many behaviors, such as unhealthy snacking or drinking, identifying critical cues may be challenging as these cues may often reflect rather subjective internal states (e.g., "boredom" or "socializing") rather than clear-cut situational cues, such as time or place (e.g., "being at home"; Adriaanse et al., 2009). Identification of these subjective internal states as critical triggers for unhealthy behaviors requires substantial introspection, which many people may lack (Nisbett $\&$ Wilson, 1977). In particular for behaviors, such as eating or drinking, that may be related to "hot" cues (e.g., feeling upset or trying to act socially), identifying these cues in a cold and rational state of planning may be difficult (e.g., Loewenstein, 1996). Studies by Adriaanse, De Ridder, and Evers (2011) and Evers, De Ridder, and Adriaanse (2009), for example, suggest that people may hold false beliefs regarding the emotional states that trigger their eating behavior.

In light of these findings it seems unlikely that participants were fully able to specify the critical cue for their habitual behavior. When future research seeks to employ cues that are truly critical, in the sense that they represent the actual triggers for performing the habitual behavior, it seems important either to use a diary to help identify the most important antecedents of the unwanted behavior (Adriaanse et al., 2009) or, alternatively, to combine the formation of counterhabitual implementation intentions with strategies that aid individuals in clarifying their personal critical cues, such as mentally contrasting the desired future outcomes of eating and drinking healthily with the obstacles of present reality (Adriaanse, Oettingen, et al., 2010; Stadler, Oettingen, \& Gollwitzer, 2009, 2010).

\section{Conclusion}

Counterhabitual implementation intentions that specify the replacement of a habitual response by an alternative response in a critical situation can change the relative strength of mental links between a habitual means and this critical situation. After forming such replacement implementation intentions, the habitual means no longer has a cognitive advantage in the horse race with the alternative response, so that both means are again truly competitive in winning the race of early activation.

\section{Declaration of Conflicting Interests}

The authors declared no potential conflicts of interests with respect to the authorship and/or publication of this article. 


\section{Financial Disclosure/Funding}

The authors received no financial support for the research and/or authorship of this article.

\section{Notes}

1. Our samples included women only, as for two of the three studies (Study 2 and 3) a motivation to eat less unhealthily was a prerequisite for participating, and this motivation appeared to be much more prevalent among women. Also, previous research has indicated that men and women differ in their eating behaviors (Nguyen-Rodriguez, Unger, \& Spruijt-Metz, 2009; Thøgersen-Ntoumani, Ntoumanis, Barkoukis, \& Spray, 2009) and respond differently to strategies promoting healthy eating behavior (Renner et al., 2008; Sepúlveda, Carrobles, Gandarillas, Poveda, \& Pastor, 2007).

2. In all three studies, reaction times were natural log transformed before entering them into the analyses, as these variables were positively skewed. However, for ease of interpretation, all reported mean scores and standard deviations are presented for the nontransformed variables (cf. Custers \& Aarts, 2007; De Houwer, 2003; Kroese, Evers, \& De Ridder, 2010).

\section{References}

Aarts, H., \& Dijksterhuis, A. (2000). Habits as knowledge structures: Automaticity in goal-directed behavior. Journal of Personality and Social Psychology, 78, 53-63.

Achtziger, A., Gollwitzer, P. M., \& Sheeran, P. (2008). Implementation intentions and shielding goal striving from unwanted thoughts and feelings. Personality and Social Psychology Bulletin, 34, 381-393.

Adriaanse, M. A., De Ridder, D. T. D., \& De Wit, J. B. F. (2009). Finding the critical cue: Implementation intentions to change one's diet work best when tailored to personally relevant reasons for unhealthy eating. Personality and Social Psychology Bulletin, $35,60-71$.

Adriaanse, M. A., De Ridder, D. T. D., \& Evers, C. (2011). Emotional eating: Eating when emotional or emotional about eating? Psychology and Health, 26, 23-39. Advance online publication. doi:10.1080/08870440903207627

Adriaanse, M. A., Oettingen, G., Gollwitzer, P. M., Hennes, E. P., De Ridder, D. T. D., \& De Wit, J. B. F. (2010). When planning is not enough: Fighting unhealthy snacking habits by mental contrasting with implementation intentions (MCII). European Journal of Social Psychology, 40, 1277-1293.

Adriaanse, M. A., Van Oosten, J. M. F., De Ridder, D. T. D., De Wit, J. B. F., \& Evers, C. (2011). Planning what not to eat: Ironic effects of implementation intentions negating unhealthy habits. Personality and Social Psychology Bulletin, 37, 69-81.

Armitage, C. J. (2007). Effects of an implementation intentionbased intervention on fruit consumption. Psychology and Health, 22, 917-928.

Bargh, J. A. (1994). The four horsemen of automaticity: Awareness, efficiency, intention, and control in social cognition. In R. S. Wyer,
Jr. \& T. K. Srull (Eds.), Handbook of social cognition (2nd ed., pp. 1-40). Hillsdale, NJ: Erlbaum.

Bargh, J. A., \& Gollwitzer, P. M. (1994). Environmental control of goal-directed action: Automatic and strategic contingencies between situations and behavior. In W. D. Spaulding (Ed.), Integrative views of motivation, cognition, and emotion. Nebraska Symposium on Motivation (Vol. 41, pp. 71-124). Lincoln: University of Nebraska Press.

Bayer, U. C., Achtziger, A., Gollwitzer, P. M., \& Moskowitz, G. B. (2009). Responding to subliminal cues: Do if-then plans facilitate action preparation and initiation without conscious intent? Social Cognition, 27, 183-201.

Brandstätter, V., Lengfelder, A., \& Gollwitzer, P. M. (2001). Implementation intentions and efficient action initiation. Journal of Personality and Social Psychology, 81, 946-960.

Cohen, A. L., Bayer, U. C., Jaudas, A., \& Gollwitzer, P. M. (2008). Self-regulatory strategy and executive control: Implementation intentions modulate task switching and Simon task performance. Psychological Research, 72, 12-26.

Custers, R., \& Aarts, H. (2007). In search of the nonconscious sources of goal pursuit: Accessibility and positive affective valence of the goal state. Journal of Experimental Social Psychology, 43, 312-318.

Danner, U. N., Aarts, H., \& De Vries, N. K. (2007). Habit formation and multiple means to goal attainment: Repeated retrieval of target means causes inhibited access to competitors. Personality and Social Psychology Bulletin, 33, 1367-1379.

Danner, U. N., Aarts, H., \& De Vries, N. K. (2008). Habit vs. intention in the prediction of future behaviour: The role of frequency, context stability and mental accessibility of past behaviour. British Journal of Social Psychology, 47, 245-265.

De Houwer, J. (2003). The extrinsic affective Simon task. Experimental Psychology, 50, 77-85.

Evers, C., De Ridder, D. T. D., \& Adriaanse, M. A. (2009). Assessing yourself as an emotional eater: Mission impossible? Health Psychology, 28, 717-725.

Fishbach, A., Friedman, R. S., \& Kruglanski, A. W. (2003). Leading us not unto temptation: Momentary allurements elicit overriding goal activation. Journal of Personality and Social Psychology, 84, 296-309.

Gawrilow, C., \& Gollwitzer, P. M. (2008). Implementation intentions facilitate response inhibition in ADHD children. Cognitive Therapy and Research, 32, 261-280.

Gollwitzer, P. M. (1999). Implementation intentions: Strong effects of simple plans. American Psychologist, 54, 493-503.

Gollwitzer, P. M., Bayer, U. C., \& McCulloch, K. C. (2005). The control of the unwanted. In R. R. Hassin, J. S. Uleman, \& J. A. Bargh (Eds.), The new unconscious (pp. 485-516). Oxford, England: Oxford University Press.

Gollwitzer, P. M., \& Sheeran, P. (2006). Implementation intentions and goal achievement: A meta-analysis of effects and processes. Advances in Experimental Social Psychology, 38, 69-119.

Holland, R. W., Aarts, H., \& Langendam, D. (2006). Breaking and creating habits on the working floor: A field-experiment on the 
power of implementation intentions. Journal of Experimental Social Psychology, 42, 776-783.

Kroese, F. M., Evers, C., \& De Ridder, D. T. D. (2010). Tricky treats: Paradoxical effects of temptation strength on selfregulation processes. European Journal of Social Psychology. Advance online publication. doi:10.1002/ejsp.771

Kruglanski, A. W., Shah, J. Y., Fishbach, A., Friedman, R. S., Chun, W. Y., \& Sleeth-Keppler, D. (2002). A theory of goal systems: Implications for social cognition, affect, and action. In M. Zanna (Ed.), Advances in experimental social psychology (Vol. 34, pp. 331-376). New York, NY: Academic Press.

Loewenstein, G. (1996). Out of control: Visceral influences on behavior. Organizational Behavior and Human Decision Processes, 65, 272-292.

Mendoza, S. A., Gollwitzer, P. M., \& Amodio, D. M. (2010). Reducing the expression of implicit stereotypes: Reflexive control through implementation intentions. Personality and Social Psychology Bulletin, 36, 512-523.

Nguyen-Rodriguez, S. T., Unger, J. B., \& Spruijt-Metz, D. (2009). Psychological determinants of emotional eating in adolescence. Eating Disorders, 17, 211-224.

Nisbett, R., \& Wilson, T. (1977). Telling more than we can know: Verbal reports on mental processes. Psychological Review, 84, 231-259.

Otis, N., \& Pelletier, L. G. (2008). Women's regulation styles for eating behaviors and outcomes: The mediating role of approach and avoidance food planning. Motivation and Emotion, 32, 55-67.

Parks-Stamm, E. J., Gollwitzer, P. M., \& Oettingen, G. (2007). Action control by implementation intentions: Effective cue detection and efficient response initiation. Social Cognition, 25, 248-266.

Renner, B., Kwon, S., Yang, B.-H., Paik, K.-C., Kim, S. H., Roh, S., . . Schwarzer, R. (2008). Social-cognitive predictors of dietary behaviors in South Korean men and women. International Journal of Behavioral Medicine, 15, 4-13.

Schweiger Gallo, I., \& Gollwitzer, P. M. (2007). Implementation intentions: Control of fear despite cognitive load. Psicothema, 19, 280-285.

Schweiger Gallo, I., Keil, A., McCulloch, K. C., Rockstroh, B., \& Gollwitzer, P. M. (2009). Strategic automation of emotion regulation. Journal of Personality and Social Psychology, 96, 11-31.

Sepúlveda, A. R., Carrobles, J. A., Gandarillas, A., Poveda, J., \& Pastor, V. (2007). Prevention program for disturbed eating and body dissatisfaction in a Spanish university population: A pilot study. Body Image, 4, 317-328.

Shah, J. Y., Friedman, R., \& Kruglanski, A. W. (2002). Forgetting all else: On the antecedents and consequences of goal shielding. Journal of Personality and Social Psychology, 83, 1261-1280.

Sheeran, P., Aubrey, R., \& Kellett, S. (2007). Increasing attendance for psychotherapy: Implementation intentions and the selfregulation of attendance-related negative affect. Journal of Consulting and Clinical Psychology, 75, 853-863.
Sheeran, P., Milne, S. E., Webb, T. L., \& Gollwitzer, P. M. (2005). Implementation intentions. In M. Conner \& P. Norman (Eds.), Predicting health behavior (2nd ed., pp. 276-323). Buckingham, England: Open University Press.

Sheeran, P., \& Orbell, S. (1999). Implementation intentions and repeated behaviour: Augmenting the predictive validity of the theory of planned behaviour. European Journal of Social Psychology, 29, 349-369.

Sheeran, P., Webb, T. L., \& Gollwitzer, P. M. (2005). The interplay between goal intentions and implementation intentions. Personality and Social Psychology Bulletin, 31, 87-98.

Stadler, G., Oettingen, G., \& Gollwitzer, P. M. (2009). Effects of a self-regulation intervention on women's physical activity. American Journal of Preventive Medicine, 36, 29-34.

Stadler, G., Oettingen, G., \& Gollwitzer, P. M. (2010). Intervention effects of information and self-regulation on eating fruits and vegetables over two years. Health Psychology, 29, 274-283.

Stewart, B. D., \& Payne, B. K. (2008). Bringing automatic stereotyping under control: Implementation intentions as efficient means of thought control. Personality and Social Psychology Bulletin, 34, 1332-1345.

Sullivan, H. W., \& Rothman, A. J. (2008). When planning is needed: Implementation intentions and attainment of approach versus avoidance health goals. Health Psychology, 27, 438-444.

Thøgersen-Ntoumani, C., Ntoumanis, N., Barkoukis, V., \& Spray, C. M. (2009). The role of motivation to eat in the prediction of weight control behaviors in female and male adolescents. Eating Behaviors, 10, 107-114.

Verplanken, B. (2006). Beyond frequency: Habit as a mental construct. British Journal of Social Psychology, 45, 639-656.

Verplanken, B., \& Aarts, H. (1999). Habit, attitude, and planned behaviour: Is habit an empty construct or an interesting case of automaticity? European Review of Social Psychology, 10, 101-134.

Verplanken, B., \& Wood, W. (2006). Interventions to break and create consumer habits. Journal of Public Policy and Marketing, $25,90-103$.

Webb, T. L., \& Sheeran, P. (2006). Does changing behavioral intentions engender behavioral change? A meta-analysis of the experimental evidence. Psychological Bulletin, 132, 249-268.

Webb, T. L., \& Sheeran, P. (2007). How do implementation intentions promote goal attainment? A test of component processes. Journal of Experimental Social Psychology, 43, 295-302.

Webb, T. L., \& Sheeran, P. (2008). Mechanisms of implementation intention effects: The role of goal intentions, self-efficacy, and accessibility of plan components. British Journal of Social Psychology, 47, 373-395.

Webb, T. L., Sheeran, P., \& Luszczynska, A. (2009). Planning to break unwanted habits: Habit strength moderates implementation intention effects on behaviour change. British Journal of Social Psychology, 48, 507-523. 